\title{
INTERDISCIPLINARIDADE EM CURSOS ONLINE: DA ATUAÇÃO DOCENTE ÀS ESTRATÉGIAS INSTRUCIONAIS
}

\author{
RIO DE JANEIRO/RJ MAIO/2018
}

\author{
Thayane Rodrigues dos Santos - lbmec - thayane.santos@ibmec.edu.br \\ Juliana Monteiro de Menezes Tenorio - lbmec - juliana.tenorio@ibmec.edu.br
}

Tipo: Investigação Científica (IC)

Natureza: Descrição de Projeto em Andamento

Categoria: Métodos e Tecnologias

Setor Educacional: EDUCAÇÃO SUPERIOR

\begin{abstract}
RESUMO
Este trabalho apresenta uma análise sobre a implantação e especificidades de uma metodologia de caráter interdisciplinar em cursos de MBA a distância do Ibmec Online. A partir da observação das características dos alunos, foi possível identificar a necessidade de uma metodologia mais aderente ao perfil do corpo discente, apresentando um curso com a arquitetura que estimula o pensamento sistêmico e coloca o aluno como protagonista do seu processo de aprendizagem. Nesse sentido, $o$ artigo aborda a metodologia interdisciplinar no contexto da educação executiva, seu processo de implantação e os resultados atingidos depois do período de maturação do modelo.
\end{abstract}

Palavras-chave: Educação a Distância; Interdisciplinaridade; Aprendizagem baseada em problemas. 


\section{Introdução}

É notório que a Educação a Distância está em crescente avanço, tanto em relação ao número de cursos ofertados por diversas Instituições de Ensino, quanto ao número de alunos que buscam essa modalidade. Como trazer um diferencial em meio à variadas ofertas? O presente artigo busca responder a esta pergunta, a partir de uma análise da metodologia aplicada no Ibmec Online, que oferece cursos a distância de pós-graduação e extensão, tendo como base a heutagogia no processo de ensino-aprendizagem.

A heutagogia, termo recentemente criado por Hase e Kenyon (2000), sustenta necessidades de aprendizagem no modelo de educação online, mas propriamente dito, da proposta estabelecida neste artigo. Um modelo interdisciplinar, tecnológico e baseado em competências, sendo os alunos corresponsáveis em seus processos de aprendizagem. O objetivo do presente artigo, portanto, é apresentar o modelo adotado nos programas de MBAs bem como as bases teóricas que o sustentam, o contexto em que se deu a implantação do modelo interdisciplinar, os desafios enfrentados durante 0 processo e finalmente, os resultados atingidos.

\section{Contexto}

O modelo de educação nos cursos online precisa ser revisitado e atualizado periodicamente para estar em linha com as demandas que o mercado apresenta, e também como o perfil do corpo discente, para que seja possível um aprendizado significativo. Behar, Bernardi e Passerino (2007) sustentam que o modelo vigente na sociedade Industrial não apresenta qualquer relação com o cotidiano do aluno, não desperta a curiosidade, e o conteúdo somente é repassado de maneira desarticulada. Dessa maneira, não sendo possível despertar o interesse do aluno, pois ele não percebe sentido no que é transmitido.

Já na sociedade em rede, os autores contrapõem o processo de aprendizagem como uma apropriação do conhecimento que é apoiado pela experiência do próprio aluno e guiado pelo professor, que orquestra a construção do conhecimento. Ou seja, o aluno assume o papel de protagonista nesse processo. Partindo desse pressuposto, sendo 0 aluno responsável pelo seu processo de aprendizagem, fez-se necessária uma análise do perfil dos alunos que compõem os cursos de pós-graduação, para que fosse possível um olhar mais centrado em suas necessidades e desenvolver um modelo a partir das particularidades encontradas. A figura a seguir apresenta a faixa etária dos alunos 
matriculados.

Figura 1 - Faixa etária dos alunos do MBA

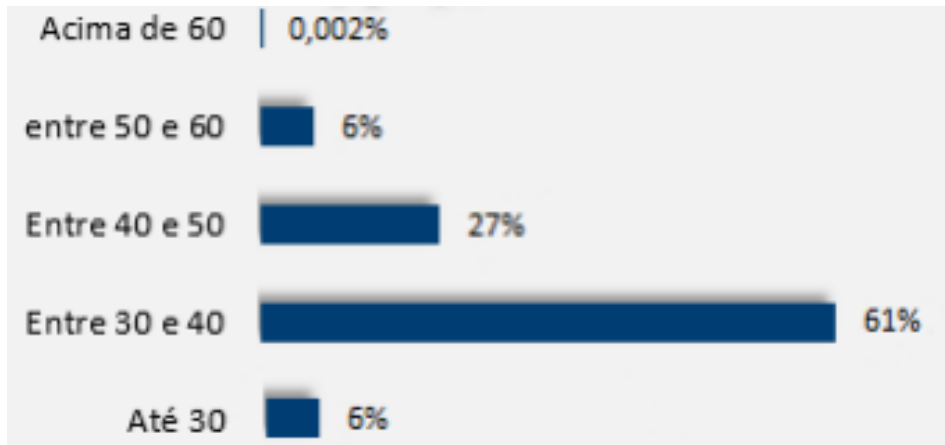

Fonte: Elaborado pelo autor

Ao analisar o gráfico, observamos que $61 \%$ dos alunos estão na faixa etária de 30 a 40 anos de idade, sendo possível identificá-los como Imigrantes Digitais (PRENSKY, 2001). Mark Prensky (2001) define o perfil dos alunos em dois conceitos: Nativos e Imigrantes Digitais. Entende-se por Imigrantes Digitais os alunos que precisaram se adaptar às tecnologias e desmistificar a lógica de pensamento linear, diferentemente dos Nativos Digitais, que já nasceram imersos no mundo tecnológico. Desta forma, os alunos inseridos nesse formato de ensino precisam desenvolver uma espécie de sabedoria digital (PRENSKY, 2012), que está diretamente ligada à necessidade deste aluno em adaptar-se significativamente a novos formatos de ensino, criando relações com suas necessidades profissionais e pedagógicas.

Sendo o aluno figura principal desse processo, ele mesmo detém o sentido e ações que são significativos para seu conhecimento. Paralelamente, pode enxergar relações entre os assuntos disponíveis para estudo, trazendo, assim, a necessidade de uma visão interdisciplinar como metodologia pedagógica, para que seja possível atender este perfil de aluno.

Observando os comentários do corpo discenteem pesquisas internas e, também, em meios informais, é possível perceber que os alunos, no qual esta análise se refere, são imediatistas e sentem a necessidade de enxergar suas rotinas profissionais naquilo que estudam, somado ao fato de que o perfil profissional desse aluno (figura 2) sugere que, em algum momento, eles tiveram contato com os assuntos abordados no MBA em seu dia a dia profissional. É neste cenário que a metodologia a ser descrita neste artigo surge, trazendo uma proposta interdisciplinar para criar relações e trazer sentido aos alunos. 
Figura 2 - Cargos dos alunos MBA

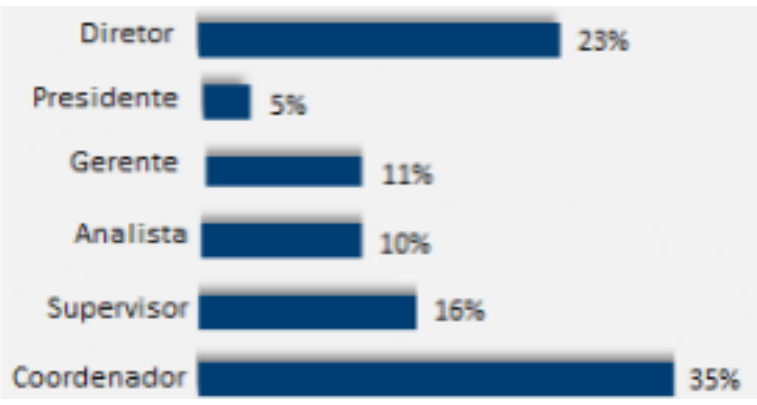

Fonte: Elaborado pelo autor

Como pode ser observado na Figura 2, o perfil dos alunos, em sua maioria, é característico de perfis profissionais que, em sua essência, precisam ser interdisciplinares. O papel do profissional hoje no mercado não fica centrado apenas em funções singulares, este precisa estar em total sinergia com outras áreas e, inclusive, lidar com situações que exijam dele uma característica de um pensamento sistêmico. Deaquino (2007) destaca três linhas de pensamento: o cartesiano, que é a base da cultura atual, sendo linear, onde um passo só é dado após o anterior ter sido completamente concluído. Em contraponto, o pensamento sistêmico, que sustenta a ideia de que o processo pode ser independente. Já o pensamento complexo pressupõe que deva ser necessário avaliar quando usar o pensamento cartesiano e quando usar o sistêmico. Segundo o mesmo autor,

esse processo deve ser transdisciplinar, ou seja, deve existir a necessidade de se conhecer o todo e criá-lo por meio de uma estreita inter-relação das partes (vertente sistêmica), porém respeitando-se a ordem mais favorável de ocorrência delas (vertente cartesiana) de acordo com as características pessoais. (DEAQUINO, 2007, p. 29).

Essa afirmação contextualiza a proposta metodológica em debate neste artigo, que tem como objetivo relacionar o processo de aprendizagem de forma significativa, partindo do pressuposto de que o aluno necessita relacionar o todo que está sendo apresentado para ele, para que ele faça relações (sistêmicas ou cartesianas) de acordo com o seu perfil. A proposta interdisciplinar e aberta apresenta ao aluno: relações e significado.

\section{Metodologia}

A metodologia dos cursos de pós-graduação na modalidade online do lbmec pressupõe a interação, por meio interdisciplinar, entre as disciplinas do curso. Foi desenvolvida uma grade curricular dividida em módulos, que são compostos por disciplinas 
relacionadas, para que o processo de interdisciplinaridade seja possível.

Figura 3 - Exemplo de um módulo e as disciplinas que o compõe

\begin{tabular}{|l|l|}
\hline Módulo & Disciplinas \\
\hline \multirow{3}{*}{ Governança e Planejamento } & Planejamento Tributário \\
\cline { 2 - 2 } & Governança Corporativa \\
\cline { 2 - 2 } & Economia Empresarial \\
\hline
\end{tabular}

Fonte: Elaborado pelo autor

Desta forma, faz-se necessário um trabalho colaborativo entre todo o corpo docente e equipe pedagógica. Todos os módulos do curso possuem assuntos que se complementam, e o intuito é que o trabalho seja construído pelos professores de forma coletiva, em grupos. Esse trabalho dá sentido ao modelo proposto e traz ao aluno uma visão integrada, possibilitando que ele articule os conhecimentos adquiridos no curso com sua própria trajetória profissional, construindo novos saberes.

Assim, o trabalho pedagógico realizado pela equipe pedagógica junto aos professores, tem por objetivo $p$ projeto inicial claro, coerente e detalhado para que as pessoas envolvidas se sintam motivadas a fazer parte dele (FAZENDA, 2012).

O trabalho docente, em conjunto com a equipe pedagógica, pretende resultar em um processo de aprendizagem que seja conectado com o "aprender fazendo" (TAKEUCHI e NONAKA, 2008), tornando a relação professor-aluno possível à troca e, consequentemente, a internalização do aprendizado. $O$ papel do professor nesse modelo, pressupõe a figura de um mediador capaz de criar um espaço de interação tanto entre as disciplinas (interdisciplinaridade), quanto entre os próprios alunos desenvolvendo atividades que possibilitem diálogo e reflexões, resultando em uma "rede" de conhecimento, segundo Takeuchi e Nonaka (2008).

Por ser tratar de uma escola de negócios, o perfil docente é, em sua maioria, oriundo de programas de mestrados profissionais e inseridos no dia a dia do mercado de trabalho, ou seja, traziam pouco ou nenhum conhecimento específico em educação, além de saberem operar os recursos disponíveis no AVA. Portanto, foi preciso uma orientação específica e dialógica com o universo da Educação, principalmente na modalidade a distância.

Por conta disso, ao longo do percurso, foram necessárias reuniões para apresentação 
do modelo pedagógico, além de ações de educação continuada que contaram com turmas específicas de capacitação, e abordaram a interdisciplinaridade como tema central. Em linha com o que Fazenda (2012) sustenta, esse apoio é fundamental para que o corpo docente repense novas práticas de ensino, já que, se faz necessária a atuação de um agente que auxilie o professor a repensar sua prática docente, bem como a de seus colegas, e ainda promover a integração da equipe de professores que atuarão juntos no projeto.

Esse processo de orientação e alinhamento é chamado pela equipe pedagógica de Mentoria. O processo de mentoria no lbmec Online compreende o período de preparação e orientação do grupo de professores que antecede o início de um módulo. Durante esse momento de preparação e orientação, a equipe pedagógica acompanha o processo de desenvolvimento das aulas e atividades propostas pelos professores para que todo o conteúdo esteja em alinhamento com a perspectiva interdisciplinar. A mentoria é de extrema importância para o sucesso na implantação do modelo pedagógico, já que é o corpo docente que está em contato direto com os alunos, sendo os responsáveis pela efetiva dinamização de todo o processo de aprendizagem. Borochovicius e Tortella (2014) sustentam a ideia de que os professores interdisciplinares devem saber trabalhar em equipe, trabalhar os interesses em comum bem como atuar em projetos compartilhados.

A interdisciplinaridade envolve a associação, colaboração, cooperação, complementação e integração entre as disciplinas, e os professores devem socializar não apenas seus conhecimentos, mas também suas experiências e visões do mundo (FAZENDA, 1979; GARCIA, 2004 apud BOROCHOVICIUS, TORTELLA, 2014).

Fazenda (2012), apoia a afirmação de que os professores devem possibilitar a troca e estimular o autoconhecimento, promovendo, assim, uma relação entre os saberes e, consequentemente, uma maior apropriação daquilo que se aprende. Para que esta constatação seja efetiva, a equipe de professores responsáveis pelas disciplinas que compõem um módulo, trabalha em conjunto no processo de mentoria, para que tenham acesso ao conteúdo dos demais assuntos, troquem informações e alinhem suas expectativas para que o resultado seja satisfatório e condizente aos parâmetros da metodologia. Desta forma, todas as atividades são desenvolvidas, tendo como espinha dorsal um estudo de caso amplo, possibilitando uma avaliação interdisciplinar, onde as questões e toda a reflexão que a avaliação traz, gire em torno desse caso, sendo possível observar as conexões entre os assuntos abordados.

Essa conexão interdisciplinar, alinhada com a apresentação de estudos de caso, traz à metodologia a aplicação de uma aprendizagem baseada em problemas (ABP), relacionando totalmente o conceito de interdisciplinaridade com a ABP. A aprendizagem 
baseada em problemas, possibilita uma relação entre teoria e prática, característica necessária para os cursos de MBA aqui citados, capaz de promover e desenvolver habilidades e competências profissionais, segundo Borochovicius e Tortella (2014), relacionando as necessidades do corpo discente e, inclusive, do corpo docente.

Dos discentes, pois o método permite que os alunos resolvam problemas relacionados as suas futuras profissões e os estimulam a pesquisar tornando-os capazes de aprender a aprender, serem críticos e tomarem decisões. Dos docentes porque os estimulam a pesquisarem e buscarem a interdisciplinaridade, fazendo conexão daquilo que estão ensinando com uma gama de informações necessárias aos futuros profissionais. Da sociedade, pois em função da alta competitividade, concorrência e um cenário globalizado e repleto de rápidas mudanças no mundo do trabalho, recebe um profissional apto a buscar soluções condizentes com a realidade e suas necessidades. (BOROCHOVICIUS e TORTELLA, 2014, p. 273)

Dessa forma, toda a estrutura que compreende a metodologia descrita neste artigo, relaciona a questão interdisciplinar, sustentada por uma aprendizagem baseada em problemas, tanto para relacionar teoria e prática, quanto para possibilitar um trabalho integrado pela equipe de professores, com o objetivo final de trazer sentido à vivência pessoal e profissional dos alunos.

\section{Desafios e Resultados}

No lançamento deste modelo pedagógico nos cursos do lbmec Online, como em qualquer grande mudança de metodologia, alguns desafios surgiram. O primeiro deles foi identificar que o modelo não é escalável, já que para ser possível uma entrega de qualidade com as características propostas, a quantidade de alunos por turma deve ser restrita para garantir que o processo de construção do conhecimento colaborativo seja efetivo.

O trabalho com professores de perfis acadêmicos heterogêneos demanda uma atuação grande da equipe pedagógica junto ao corpo docente. Essa atuação se divide em três momentos distintos: 1) Capacitação dos docentes e ações de educação continuada onde o objetivo é articulado em dois eixos: o entendimento da interdisciplinaridade bem como a interdisciplinaridade no contexto da EAD, com a aplicabilidade dos recursos e ferramentas que a modalidade dispõe; 2) Mentoria, conforme descrita na seção anterior, compreende as ações pré-aula, ou seja, trabalho em conjunto com os demais docentes do mesmo módulo com objetivo de promover a integração entre os professores para o desenvolvimento das atividades integradoras; e 3) Acompanhamento no tocante as aulas em si, todas as ações dos professores na plataforma são assistidas pela equipe pedagógica a fim de assegurar a realização, garantindo que o modelo proposto seja 
seguido.

Outro desafio percebido esteve na orientação das pontas: desde o alinhamento das expectativas no momento da matrícula até o atendimento ao aluno, para que fosse possível uma compreensão da metodologia e do formato que o curso pressupõe. Essa preocupação se deu pelo simples fato de que são as pontas (atendimento e matrícula de alunos) que são o contato direto com o aluno no que diz respeito à orientação e dúvidas sobre o formato.

Após o período de maturação do modelo, que durou cerca de um ano, tivemos um aumento de trinta pontos percentuais no resultado da pesquisa, que avalia o nível de satisfação dos alunos com relação à metodologia dos cursos. É possível considerar que esse aumento ocorreu devido ao fato de que todas as áreas e pessoas envolvidas na ação também passaram por um processo de maturação, tanto com relação à percepção da metodologia, quanto ao entendimento das características e especificidades que ela possui.

Desta forma, foi possível observar uma diminuição do índice de evasão dos cursos e, paralelamente, o aumento do engajamento do professor na atuação docente do atual modelo pedagógico, o que resultou nos índices positivos acima citados. Como exemplo, no depoimento a seguir, extraído da pesquisa de satisfação, é possível observar o entendimento do aluno sobre a metodologia proposta: "Excelente curso, excelentes professores. A metodologia nos coloca como protagonistas da aprendizagem o que gera mais motivação e comprometimento!".

Por fim, o presente artigo procurou sintetizar e esclarecer de forma ampla a proposta de uma metodologia inovadora que tem por objetivo trazer ao aluno uma visão interdisciplinar e fazer com que ele possa sentir-se como peça chave no seu processo de aprendizado. Os resultados obtidos até o momento são satisfatórios e reforçam a ideia de que um modelo interdisciplinar, além de estimular um pensamento sistêmico, agrega valor profissional e promove uma aprendizagem significativa.

\section{Referências}

BEHAR, Patricia A., BERNARDI, Maira e PASSERINO, Liliana. Modelos Pedagógicos para Educação a Distância: pressupostos teóricos para a construção de objetos de

Dez.

2007.

Disponível

em: 
www.cinted.ufrgs.br/ciclo10/artigos/4bPatricia.pdf, acesso em 08 de maio de 2018.

BOROCHOVICIUS, Eli. TORTELLA, Jussara Cristina Barboza. Aprendizagem Baseada em Problemas: um método de ensino-aprendizagem e suas práticas educativas. In: Ensaio: aval. pol. públ. Educ., Rio de Janeiro, v.22, n. 83, p. 263-294, abr./jun. 2014. Disponível em: http://www.scielo.br/pdf/ensaio/v22n83/a02v22n83.pdf, acesso em 16 de Maio de 2018.

DEAQUINO, Carlos Tasso Eita. Como aprender: andragogia e as habilidades de aprendizagem. $1^{\text {a }}$ Ed. - São Paulo: Pearson Prentice Hall, 2007.

FAZENDA, Ivani Catarina Arantes. Interdisciplinaridade: História, teoria e pesquisa. $18^{\mathrm{a}}$ ed. Campinas, SP: Papirus, 2012.

KENYON, Chris; HASE, Stewart. Moving from andragogy to heutagogy in vocation education.

Disponível

em:

https://epubs.scu.edu.au/cgi/viewcontent.cgi?referer=https://www.google.com.b

r/\&httpsredir=1\&article=1147\&context=gcm_pubs, acesso em 30 de Abril de 2018.

PRENSKY, Marc. Digital Natives, Digital Immigrants Part 1. On the Horizon, 2001 Vol. 9 Iss: 5, p. $1-6$

Brain Gain: Technology and the quest for digital. 1.ed.Editora Palgrave Macmillan, 2012.

TAKEUCHI, Hirotaka. NONAKA, Ikujiro. Gestão do conhecimento. Porto Alegre: Bookman, 2008. 